\title{
AXEL HONNETH E NANCY FRASER: DILEMAS ENTRE O RECONHECIMENTO E A REDISTRIBUIÇÃO
}

\author{
AXEL HONNETH Y NANCY FRASER: DILEMAS ENTRE RECONOCIMIENTOY \\ REDISTRIBUCIÓN
}

\author{
AXEL HONNETH AND NANCY FRASER: DILEMMAS BETWEEN RECOGNITION \\ AND REDISTRIBUTION
}

\author{
Pedro Luís PANIGASSI ${ }^{1}$
}

RESUMO: O artigo objetiva situar o debate inserido no campo teórico da Teoria Crítica entre Axel Honneth e Nancy Fraser, tendo em vista suas principais publicações na década de 1990. Desde o modelo crítico formulado por Jürgen Habermas, a Teoria Crítica passou a dar uma ênfase maior às questões envolvendo a teoria política normativa, com foco nos novos movimentos sociais que surgiram após o maio de 1968. Nesse sentido, Honneth e Fraser apresentam novas contribuições para esta discussão, com vista à formulação de novas propostas normativas. Desse modo, a partir de uma análise qualitativa bibliográfica dos textos propostos, centraremos a exposição em torno dos conceitos de reconhecimento e redistribuição a fim de compreender a importância das principais questões postas pelos autores.

PALAVRAS-CHAVE: Teoria crítica. Reconhecimento. Redistribuição.

RESUMEN: El artículo tiene como objetivo situar el debate elaborado dentro del campo teórico de la Teoría Crítica entre Axel Honneth y Nancy Fraser, a la vista de sus principales publicaciones en la década de 1990. Desde el modelo crítico formulado por Jürgen Habermas, la Teoría Crítica ha pasado a poner un mayor énfasis las preguntas que involucran la teoría política normativa, enfocándose en los nuevos movimientos sociales surgidos después de mayo de 1968. En este sentido, Honneth y Fraser presentan nuevos aportes a esta discusión, con miras a formular nuevas propuestas normativas. Así, a partir de un análisis bibliográfico cualitativo de los textos propuestos, centraremos la exposición en torno a los conceptos de reconocimiento y redistribución con el fin de comprender la importancia de las principales cuestiones planteadas por los autores.

PALABRAS CLAVE: Teoría crítica. Reconocimiento. Redistribución.

ABSTRACT: The article aims to situate the debate drawn within the theoretical field of Critical Theory between Axel Honneth and Nancy Fraser, in view of their main publications in the 1990s. Since the critical model formulated by Jürgen Habermas, Critical Theory has come to place a greater emphasis in the questions involving normative political theory, focusing on the new social movements that emerged after May 1968. In this sense, Honneth

${ }^{1}$ Universidade Estadual Paulista (UNESP), Araraquara - SP - Brasil. Graduando em Ciências Sociais. ORCID: https://orcid.org/0000-0002-0053-768X. E-mail: pedro.panigassi@unesp.br 
and Fraser present new contributions to this discussion, with a view to formulating new normative proposals. Thus, based on a qualitative bibliographic analysis of the proposed texts, we will focus the exposition on the concepts of recognition and redistribution in order to understand the importance of the main questions posed by the authors.

KEYWORDS: Critical Theory. Recognition. Redistribution.

\section{Introdução}

Desde que Habermas $(2000 ; 2012)$ buscou ir além da primeira geração da Teoria Crítica propondo a ideia de uma razão comunicativa, apontando para os limites da crítica da razão operada por Max Horkheimer e Theodor Adorno (1985), a filosofia social passou a enveredar-se pelo campo da teoria política normativa, procurando oferecer respostas para o seu tempo histórico, mediante a força que os novos movimentos sociais adquiriram na esfera pública. Nesse sentido, nos anos 1990 e no início dos anos 2000, Axel Honneth e Nancy Fraser traçaram um debate fundamental na tentativa de contribuir com as novas lutas sociais que surgiram neste período, tendo como eixo central os termos reconhecimento $\mathrm{e}$ redistribuição.

Contextualizando a importância deste debate dentro da Teoria Política e da própria Teoria Crítica, o presente artigo objetiva expor e explicar alguns pontos fundamentais delineados por ambos os autores, a fim de refletir a relevância que os conceitos de reconhecimento e redistribuição obtiveram no debate público contemporâneo. Para este empreendimento, realizaremos uma análise bibliográfica qualitativa, tendo como principal referência o livro Luta por reconhecimento, obra em que Honneth dá corpo pela primeira vez ao conceito de reconhecimento, e o texto "Redistribución y Reconocimiento", no qual Fraser sintetiza suas principais críticas à noção de reconhecimento e propõe sua conciliação com as lutas por redistribuição.

\section{A luta por reconhecimento em Axel Honneth}

Axel Honneth resgata a centralidade da filosofia política enquanto ciência capaz de desenvolver conhecimentos que possam, efetivamente, compreender as novas lutas sociais que se desenvolviam no interior de sociedades cada vez mais complexas, tensionadas e plurais. Em sua obra intitulada Luta por reconhecimento: a gramática moral dos conflitos sociais, advinda de sua tese de livre-docência, o autor empreende um esforço cognitivo na tentativa de articular teoria e realidade empírica, uma vez que, na realidade social na qual ele 
estava inserido, manifestavam-se novas lutas por reconhecimento, que colocaram o autor diante da necessidade de elaborar um pensamento crítico que fosse capaz de compreender o senso e o significado das relações sociais concretas e, a partir disso, das inerentes contradições, paradoxos e ambivalências contidas no interior das novas lutas sociais que se manifestavam em seu tempo histórico.

Desse modo, é importante delimitarmos a tradição que Honneth se filia, a saber: a Teoria Crítica. Em sentido restrito, este termo refere-se aos autores do início do século XX que participaram do Instituto de Pesquisa Social de Frankfurt (caso, por exemplo, de Theodor Adorno, Max Horkheimer, Herbert Macurse). Em sentido amplo, tendo em vista o texto programático redigido por Horkheimer em 1932 intitulado "Teoria Tradicional e Teoria Crítica", o termo refere-se aos autores que se filiam a Marx a partir de dois princípios fundamentais, são eles: o comportamento crítico e a orientação para a emancipação (NOBRE, 2004). A primeira geração, a qual Max Horkheimer e Theodor Adorno integraram, procurou compreender o sentido e o significado do capitalismo no século XX, bem como de uma sociedade capitalista que se consolidava enquanto uma nova totalidade que se desenvolvia a partir do declínio, sempre mais acelerado, das antigas "potências de formação cultural" (HOKHEIMER, 1990). De um modo geral, podemos afirmar que a Teoria Crítica está preocupada em compreender os motivos, as causas de um acúmulo das crises sociais (a predominância do sistema econômico, político, a ascensão de novos valores e a partir disso a capacidade de uma força social reescrever a moral), bem como compreender como surge uma nova ordem social, qual o senso da história passando, por fim, pelas novas formas de autoridade, dominação e poder.

Em Luta por reconhecimento: a gramática moral dos conflitos sociais, Honneth aponta para o fato de que a Teoria Crítica passa a associar-se, também, aos processos de construção social da identidade (pessoal e coletiva), tendo em sua gramática uma luta por reconhecimento e atribuindo grande ênfase à noção de um "conflito" enquanto elemento constitutivo da subjetividade e da identidade (pessoal e coletiva) dos membros de determinada sociabilidade. Em sua tese de doutorado intitulada Crítica del poder, em que Honneth propõe um "acerto de contas" com autores fundamentais do século XX, a saber, Adorno, Horkheimer, Habermas e Foucault, ele busca apresentar uma análise crítica da realidade social que não seja neutra. Nesse sentido, retomando ideais normativos imantes, isto é, partindo de potenciais intramundanos de transformação da realidade social, o filósofo alemão propõe um modelo crítico inspirado no materialismo interdisciplinar de Max Horkheimer. No entanto, em um sentido diferente daquele posto na década de 1920. Com vista à emergência dos novos 
movimentos sociais nas décadas de 1970 e 1980, ele defende o uso da ideia de luta por reconhecimento para entender a estrutura da forma de reinvindicação de direitos no mundo atual. Assim, ao colocar o conflito social como fundamental em seu projeto crítico, Honneth acreditava estar superando os padrões críticos estabelecidos por Horkheimer, na medida em que este estava fechado em um ciclo entre a dominação capitalista e a análise cultural, o que caracterizaria um déficit sociológico em sua obra, visto que não seria capaz de distinguir os contextos práticos da Teoria Crítica dos da teoria tradicional. Dessa maneira, o autor (HONNETH, 2009) elege o conflito como ponto central de sua teoria.

Honneth (2009, p. 30) recorre aos escritos de Hegel durante seu período de juventude em Jena, para opor-se ao paradigma presente na filosofia política moderna (em Maquiavel e Hobbes), qual seja: a compreensão de que a sociedade precede de um cálculo egoísta de autoconservação dos indivíduos, é assim que:

[...] os escritos políticos de Maquiavel preparam a concepção segundo a qual os sujeitos individuais se contrapõem numa concorrência permanente de interesses, não diferentemente de coletividades políticas; na obra de Thomas Hobbes, ela se torna enfim a base de uma teoria do contrato que fundamenta a soberania do estado (HONNETH, 2009, p. 31).

Tal concepção constitui-se em oposição à apresentada por Aristóteles e Cícero, de forma que pressupõe que os homens são seres sociais e políticos (zoon politikon), sendo a vida na pólis inerente à própria natureza humana, a finalidade dos seres, e não decorrente de uma mera escolha mecanicista. A família, para Aristóteles (2002), seria uma demanda natural e formaria uma "primeira" sociedade, seguida pela aldeia e pela cidade. Assim é que, para o grego a causa final da cidade é o bem soberano e o homem, enquanto ser social se complementa na vida pública. É a partir disso que Hegel, enquanto um leitor das teorias filosóficas clássicas, irá se familiarizar com uma corrente da filosofia política que atribui à intersubjetividade da vida pública uma importância muito grande, diferentemente do que estabelecido nos pensamentos de Hobbes e Maquiavel, opondo-se, primeiramente à concepção de luta social desenvolvida por esses dois autores e, também, aos pressupostos individualistas apreendidos por ele no sistema kantiano.

Os escritos do jovem Hegel indicam, assim, na leitura de Honneth, para o fato de que os sujeitos apenas abandonam e superam as relações éticas em que se encontram na medida em que sentem que elas não são capazes de reconhecer, plenamente, o caráter particular de suas identidades. A "luta social" que se formaria a partir de tal constatação não estaria socialmente organizada como um confronto de "todos contra todos", mas sim como uma luta 
social moralmente motivada, uma vez que tem como objetivo o reconhecimento amplo da individualidade humana (HONNETH, 2009, p. 47-48). O que nos faz concluir que a necessidade da luta por reconhecimento destaca a importância da identidade subjetiva dos sujeitos, dos seus valores, caracterizando, inclusive, uma luta para que liberdade e justiça possam estar permanentemente dilatando-se. É uma luta pelo direito de ser livre e reconhecido como igual (plenamente humano), de modo que a construção do reconhecimento recíproco gera o progresso moral e substancialmente político: forma uma nova totalidade, uma potência que tem a capacidade de unificar os diversos seres humanos mediante a força de valores universais.

Podemos perceber, pela leitura que Honneth faz de Hegel, uma semelhança em relação à teoria da ação comunicativa desenvolvida por Jürgen Habermas (1987; 2012), do qual o autor foi discípulo. Ambos compartilham da ideia de uma razão intersubjetiva, contra uma razão centrada no sujeito, conforme a leitura dos escritos de Jena de Hegel. Porém, enquanto Habermas pensa a ação dentro do campo da linguagem, entendendo-a enquanto orientada para o entendimento entre os indivíduos constituindo a razão intersubjetiva, o autor leva em conta que, dentro da ideia de luta por reconhecimento, presente na constituição do pensamento de Hegel (retomando a Fichte e Hobbes), as relações intersubjetivas não se reduzem apenas linguagem e não necessariamente visam o entendimento ${ }^{2}$. É por meio de uma articulação entre a leitura de Hegel que resumimos até agora, e de fundamentos da psicologia social de George Hebert Mead e Jessica Benjamin (sendo que Mead foi quem atribuiu na visão Honneth, um caráter materialista a ideia de reconhecimento de Hegel), da vertente da psicologia ligada a Winnitcott, e dos desenvolvimentos teóricos de Marshall sobre cidadania, que o filósofo formula sua concepção de reconhecimento, que se divide em três esferas, a saber: dos afetos (amor), dos direitos (direito) e da estima social (solidariedade).

A primeira esfera, a do amor, trata-se deste no sentido das relações primárias "na medida em que elas consistam em ligações emotivas fortes entre poucas pessoas, segundo o padrão de relações eróticas entre dois parceiros, de amizades e de relações pai/filho" (HONNETH, 2009, p. 159). Honneth, neste ponto, remete a ideia de Hegel de que o amor constitui a primeira etapa do reconhecimento recíproco, visto que é o lugar no qual os sujeitos reconhecem suas carências, e entende a necessidade do outro.

2 Como destaca Bressiani (2010, p. 51), Honneth segue os passos de Habermas no sentido de efetuar um deslocamento do paradigma da produção para uma distinta forma de ação. No entanto, ele o faz de maneira distinta, pois está focado na questão da interação social voltada para o reconhecimento e não para a obtenção do entendimento. 
Nesse sentido, o filósofo alemão aponta que esta ideia da filosofia hegeliana teve seu desenvolvimento nos estudos do psicanalista inglês Donald W. Winnicott. O psicanalista inglês propõe, a partir da ideia de "narcisismo primário" de Freud, a ideia de que a criança tem, em um primeiro estágio, a tendência a uma onipotência a partir do comportamento materno, assim como a mãe percebe todas as relações do filho como um ciclo único da ação. É como se mãe e filho fossem apenas um ser. Assim, no processo de amadurecimento infantil a cooperação intersubjetiva entre mãe e filho, através do mútuo reconhecimento, faz com que a criança se reconheça enquanto um ser autônomo. E não só a criança, mas também a mãe passa por um amadurecimento no processo de lidar com a maternidade (HONNETH, 2009, p. 164-165). Essa é a esfera, portanto, que o indivíduo adquire a autoconfiança.

A segunda esfera do reconhecimento é a da esfera jurídica, representada no direito. Aqui, Honneth trata da questão também colocada por Hegel, mas que está presente em Mead, de que o seres humanos desenvolvem-se dentro de um cerne estrutural de toda eticidade: "só aquela ligação simbioticamente alimentada, que surge da delimitação reciprocamente querida, cria a medida de autoconfiança individual, que é a vase indispensável para a participação autônoma na vida pública" (HONNETH, 2009, p. 178). Assim:

Da forma de reconhecimento do amor, como a apresentamos aqui com o auxílio da teoria das relações de objeto, distingue-se então a relação jurídica em quase todos os aspectos decisivos; ambas as esferas de interação só podem ser concebidas como dois tipos de um mesmo padrão de socialização porque sua lógica respectiva não se explica adequadamente sem o recurso ao mesmo mecanismo de reconhecimento recíproco. Para o direito, Hegel e Mead perceberam uma semelhante relação na circunstancia de que só podemos chegar a uma compreensão de nós mesmos como portadores de direitos quando possuímos, inversamente, um saber sobre quais obrigações temos de observar em face do respectivo outro: apenas da perspectiva normativa de um "outro generalizado", que já nos ensina a reconhecer os outros membros da coletividade como portadores de direitos, nós podemos nos entender também como pessoa de direito, no sentido de que podemos estar seguros do cumprimento social de algumas de nossas pretensões (HONNETH, 2009, p. 179).

Na modernidade, o direito significa a possibilidade do reconhecimento do outro, do diferente, como uma pessoa livre e igual a todas as outras. Aqui Honneth segue enquanto referências Hegel e Mead. "No que concerne ao direito, ambos perceberam que só podemos chegar a uma compreensão de nós mesmos como portadores de direitos quando sabemos quais obrigações temos de observar em face do outro" (ALBORNOZ, 2011, p. 137). A partir do momento em que concebemos os outros enquanto pessoas dotadas de direitos, é que 
podemos entender-nos também enquanto pessoas de direito, e assim podemos nos tornar seguros do cumprimento social de algumas de nossas pretensões.

Com vista o processo histórico de constituição da cidadania descrito por $\mathrm{T}$. H. Marshall, Honneth demonstra como a conquista histórica dos direitos políticos, civis e sociais, significou uma "luta por reconhecimento", por parte dos cidadãos, que se efetivou através da esfera jurídica (HONNETH, 2009, p. 191-192). Dada a situação de podermos reconhecer o ser humano enquanto pessoa, não levando em conta necessariamente suas realizações ou seu caráter, indica, como nos mostra Honneth, duas formas distintas de respeito: o reconhecimento cognitivo, no qual se distingue a estima por um determinado ser humano, e o respeito a um ser humano particular. Desse modo, é na esfera do reconhecimento dos direitos que se desenvolve a noção de "autorrespeito".

Seguindo Hegel e Mead, Honneth descreve a terceira esfera do reconhecimento recíproco que se refere à estima social, dado que "além da experiência da dedicação afetiva e do reconhecimento jurídico, de uma estima social que lhes permita referir-se positivamente a suas propriedades e capacidades concretas" (ALBORNOZ, 2011, p. 139-140). Tal compartilhamento de estima mútua entre os indivíduos, só se torna compreensível na medida em que houver um horizonte de valores partilhados entre si pelos sujeitos envolvidos. Diferente do reconhecimento jurídico moderno que possui uma visão universal em relação aos sujeitos, a estima social leva em conta as qualidades particulares que diferenciam os seres humanos, fundamentadas em vínculos intersubjetivos.

Dessa maneira, "essa forma de reconhecimento recíproco está ligada também à pressuposição de um contexto de vida social cujos membros constituem uma comunidade de valores mediante a orientação por concepções de objetivos comuns" (HONNETH, 2009, p. 200). Como demonstra Honneth, historicamente o conceito de "honra" passa a ser substituído pelas ideias de "prestígio" e "reputação" dentro da esfera pública. Esses dois conceitos referem-se ao grau de reconhecimento social que o indivíduo atinge na sociedade, dado que de algum modo contribuiu para os objetivos abstratamente definidos (HONNETH, 2009, p. 206). As sociedades modernas, portanto, caracterizam-se, nas relações de estima social, por uma luta permanente entre os grupos sociais para elevar o valor atribuído à capacidade de suas formas de vida.

Contudo, o que decide sobre o desfecho dessas lutas, estabilizado apenas temporariamente, não é apenas o poder de dispor dos meios da forca simbólica, específico de determinados grupos, mas também o clima, dificilmente influenciável, das atenções públicas: quanto mais os movimentos sociais conseguem chamar a atenção da esfera pública para a 
importância negligenciada das propriedades e das capacidades representadas por eles de modo coletivo, tanto mais existe para eles a possibilidade de elevar na sociedade o valor social ou mais precisamente a reputação de seus membros (HONNETH, 2009, 207-208).

De acordo com o autor, com este desenvolvimento, a estima social assume um padrão capaz de conferir às formas de reconhecimento associadas a ela "o caráter de relações assimétricas entre os sujeitos que são biograficamente individuados. As reputações dos sujeitos são mensuradas pelas realizações que eles apresentam socialmente dentro do quadro de autorrealização. Hegel e Mead expressam justamente esse caráter organizacional da estima social, visto que o modelo de ambos visou uma ordem social de valores "na qual as finalidades sociais passam por uma interpretação tão complexa e rica que, no fundo, todo indivíduo acaba recebendo a chance de obter reputação social" (HONNETH, 2009, p. 208). Essa terceira esfera, portanto, visa a ideia de solidariedade, isto é, a ideia de relações simétricas, nos termos da sociedade, que possibilitem qualquer sujeito de ter reconhecida as suas capacidades como valiosas e necessárias. Em virtude disso, a auto relação prática desenvolvida nessa esfera é a "autoestima".

Cada uma das esferas do reconhecimento descritas pelo autor representa uma relação prática. Quando há um desrespeito a algumas delas, é quando decorrem as lutas sociais, de forma que as lutas por reconhecimento se caracterizam, para o filósofo alemão, como motores da mudança social. Honneth possui a pretensão de complementar a ideia de eticidade a partir do conceito de uma razão intersubjetiva, isto é, práticas e valores que formam a estrutura do reconhecimento recíproco. Em outras palavras, o indivíduo encontra reconhecimento como autônomo e dentro do grupo, podendo autodesenvolver-se. O conjunto de instituições é o que garantem as três esferas do reconhecimento.

Ora, em virtude do que foi abordado, vemos que a partir da recuperação do conceito de reconhecimento e de relações intersubjetivas presentes na obra de Hegel, Honneth fórmula, também ancorado na psicologia de Mead e Winnicot, uma noção de reconhecimento que busque dar conta da formulação uma noção normativa em relação à sociedade, para que se busque realizar uma crítica a partir de tal formulação. Contudo, veremos agora com Nancy Fraser que apenas a luta por reconhecimento é insuficiente, na medida em que muitas vezes, não se levar em conta o princípio de distribuição conduz a medidas apenas afirmativas, mas não que visem à transformação e emancipação social. 


\section{Nancy Fraser: reconhecimento e redistribuição}

Nancy Fraser, assim como Honneth, filia-se a tradição da Teoria Crítica. Assim, ela inicia sua argumentação no sentido de apresentar o panorama de lutas sociais, na qual a chamada luta por reconhecimento ganha força. Nas lutas pós-socialistas, a identidade do grupo suplanta os interesses de classe como mecanismo principal de mobilização política, fazendo com que o reconhecimento cultural ganhe mais valor em relação a uma redistribuição econômica. Tendo em vista as questões da reconfiguração global pós União das Repúblicas Socialistas Soviéticas, a autora coloca, enquanto questão, como deveríamos entender o fim do imaginário socialista centrado nas definições tais como interesses, exploração e redistribuição? E, ao mesmo tempo, como interpretar o surgimento de um novo imaginário político centrado nas noções de identidade, diferença, dominação cultural e reconhecimento? Tal mudança representa a caída em estado de "falsa consciência?".

$\mathrm{Na}$ opinião da autora, nenhuma destas posturas levadas ao extremo resulta em uma forma adequada. Para Fraser, cabe que se desenvolva uma Teoria Crítica sobre o reconhecimento, que defenda unicamente aquelas versões da política cultural que possibilitem combinar-se com as políticas de igualdade e redistribuição. Ela supõe que a justiça hoje em dia requer tanto a distribuição quanto o reconhecimento, e que se deve examinar, primeiramente, a relação entre ambos. Isto significa uma tentativa de imaginar um reconhecimento cultural e uma igualdade social de maneira que ambas se apoiem, e não se excluam.

A autora propõe, de saída, analisar os dilemas paradoxais quando se comparam as políticas de reconhecimentos e distribuição. Dentro do cenário político contemporâneo póssocialista, com o descolamento das classes, diversos movimentos sociais mudam as direções de suas reinvindicações. As exigências de mudança econômica perdem espaço para as de mudança cultural, tanto dentro dos movimentos sociais como entre eles. Desta forma, as pretensões baseadas na identidade tendem a predominar cada vez mais, enquanto as perspectivas de redistribuição tendem a retroceder, resultando num campo político com entraves programáticos (FRASER, 1997, p. 19-20). Fraser propõe uma distinção analítica entre as duas concepções de injustiça. A primeira é a injustiça socioeconômica, arraigada na estrutura político-econômica da sociedade. Os exemplos desse tipo se injustiça são "la explotación (es decir, la apropiación del usufructo del trabajo proprio en beneficio de otros); la marginación económica; y la privación de los bienes materiales indispensables para llevar una vida digna" (FRASER, 1997, p. 20) 
A segunda forma é a injustiça cultural ou simbólica. Neste caso, a injustiça está nas raízes dos padrões sociais de representação, interpretação e comunicação. Os exemplos deste tipo de injustiça incluem a dominação cultural, o reconhecimento e o desrespeito (FRASER, 1997, p. 22). Tal injustiça e as lutas em torno dela, nos remetem de volta a Honneth, e em como há uma luta por reconhecimento entre os indivíduos em torno de sua honra. A própria Fraser retorna brevemente a Honneth, e a Charles Taylor, no intuito de demonstrar sua tese.

Apesar de suas diferenças, ambas as injustiças econômica e cultural se encontram, na visão de Fraser, amplamente difundidas nas sociedades contemporâneas. Elas estão arraigadas em processos e práticas que sistematicamente põe um grupo de pessoas em desvantagem frente a outras, e, portanto, devem ser solucionadas. Na prática, nos mostra a autora, as duas se entrelaçam. As instituições econômicas materiais têm uma dimensão constitutiva cultural, estando atravessadas por significações e normas, e as práticas culturais mais discursivas possuem uma dimensão político-econômica constitutiva, estando atadas a bases materiais. Estas injustiças se encontram usualmente entrelaçadas de forma que se reforçam mutualmente de maneira dialética, e tem como resultado um círculo vicioso de subordinação cultural e econômica (FRASER, 1997, p. 23).

Contudo, por motivos analíticos, Fraser mantém a distinção de ambas as injustiças, e nesse sentido propõe, da mesma forma, soluções distintas. Assim, a solução para a injustiça econômica é algum tipo de restruturação político-social, centrada na noção de redistribuição. Já a solução para injustiça cultural se vê na mudança das relações simbólicas entre os indivíduos, em torno da noção de reconhecimento. Pode haver, em muitos casos, como nos mostra Fraser, um conflito entre ambas as soluções, visto que enquanto as exigências por reconhecimento buscam afirmar uma identidade do grupo, por essa razão tendem a promover a diferenciação dos grupos, as exigências por redistribuição advogam pela abolição dos privilégios econômicos que servem de suporte para especificidade dos grupos, como por exemplo, o fato de os proletários possuírem uma desvantagem enorme em relação aos burgueses. Como consequência destas diferenciações há uma tensão entre elas, que podem fazer com que ambas entrem em conflito.

A filósofa apresenta-nos então uma distinção entre as políticas de reconhecimento e redistribuição que os diversos movimentos sociais reivindicam, sendo alguns voltados apenas para pauta da redistribuição e outros apenas voltados a pautas de reconhecimento ou, também, em casos que ambas as reivindicações então presentes. Um exemplo extremo no qual as pautas por redistribuição aparecem enquanto hegemônicas, são as da economia política, na qual, como já exemplificamos anteriormente, numa visão marxista da sociedade, os 
proletariados reivindicam, dentro de uma luta de classes, a igualdade social e o consequente fim da burguesia, para que não houvesse mais classes sociais. Em contraste, Fraser (1997, p. 26) considera outro extremo do espectro conceitual, postulando o tipo ideal de coletividade que se ajusta ao modelo de justiça por vias do reconhecimento. A raiz da injustiça é o reconhecimento cultural errôneo. Um exemplo que pode ser interpretado, segundo Fraser, de maneira aproximada seria a sexualidade menosprezada, em que a sexualidade é um modo de diferenciação social, cujas raízes não se encontram na economia política, posto que haja homossexuais em todas as classes sociais. Assim, a luta é pela valorização dos diferentes modos de sexualidade, que estes possam ser expressos livremente, contra a construção autoritária da sociedade em torno de uma "heteronormatividade".

Até então, Fraser se detém em mostrar os dilemas paradoxais que enfrentam as lutas por reconhecimento e distribuição, partindo do suposto que as soluções redistributivas tendem a diminuir a diferença entre os grupos, enquanto as de reconhecimento tendem a aumentar a diferença. Assim, a fim de aprofundar-se nas complexidades destas questões, a autora passa a examinar as concepções alternativas de redistribuição e reconhecimento, chamadas de afirmação e transformação. Primeiramente, iremos seguindo a linha de argumentação da autora, perpassar pelas definições de afirmação e transformação, para depois relacioná-las com redistribuição e reconhecimento. Por fim, demonstraremos como ela resolve os impasses abstraídos dessas considerações.

Com soluções afirmativas para as injustiças, Fraser refere-se às soluções dirigidas a corrigir os resultados desiguais dos acordos sociais, sem afetar o marco geral que os origina. Por soluções transformativas, pelo contrário, a autora entende aquelas soluções voltadas a corrigir resultados desiguais, precisamente mediante a restruturação do marco geral implícito que os origina. $\mathrm{O}$ ponto essencial do contraste é enquanto as ações afirmativas buscam uma mudança gradual, as transformativas buscam a mudança radical dessas injustiças. Para melhor distinguirmos, podemos nos ater ao exemplo das injustiças culturais. As soluções afirmativas para este tipo de injustiça se encontram associadas atualmente com o chamado "multiculturalismo central", muito difundido na figura de Charles Taylor.

Este tipo de multiculturalismo se propõe a reparar a falta de respeito mediante as identidades de grupo, porém deixa intacto o conteúdo dessas identidades como diferenciações de grupo implícitas. As soluções transformativas, pelo contrário, estão associadas atualmente com a desconstrução. A eliminação da falta de respeito, neste caso, se daria através da transformação da estrutura cultural e simbólica da sociedade. Ao desestabilizar as identidades de grupo existentes e os fatores de diferenciação, estas soluções não só elevariam a autoestima 
dos membros dos grupos desrespeitados, como também a imagem de todos os membros da sociedade sobre si mesmos (FRASER, 1997, p. 39).

$\mathrm{Na}$ esfera da injustiça econômica, as soluções afirmativas têm sido associadas historicamente com o Estado de bem-estar social. Com elas se busca reparar a má distribuição dos recursos resultantes, deixando intacta a estrutura político econômica atual. Para tanto, se busca aumentar o consumo dos grupos em desvantagem econômica, sem reestruturar o sistema de produção (FRASER, 1997). As soluções transformativas, em contraste, são associadas historicamente ao socialismo, reestruturando as relações de produção, não apenas mexendo no consumo dos indivíduos, mas mudando a divisão social do trabalho e as condições de existência de todos. Assim, Fraser demonstra que enquanto as soluções de caráter afirmativo tendem a promover a diferenciação entre os indivíduos, privilegiando determinadas classes, por exemplo; as de tipo transformativo recorrem a diluir tais diferenças dada sua concepção universalista. Soluções afirmativas também podem gerar um efeito secundário de injustiças de reconhecimento, enquanto as soluções transformativas podem contribuir para reparar algumas delas.

Tais considerações sugerem uma maneira de reformular o dilema redistribuiçãoreconhecimento. Fraser questiona então: para aqueles grupos que estão sujeitos a injustiças de ambos os tipos, que combinação de soluções funcionaria para minimizar, se não para eliminar do todo, as interferências mútuas que podem surgir quando se persegue simultaneamente a redistribuição e o reconhecimento? A autora irá propor um quadro comparativo em torno das noções de ações transformativas e afirmativas levando em conta redistribuição e reconhecimento:

Vamos imaginar uma matriz de quatro células. O eixo horizontal inclui os dois tipos gerais de soluções que acabamos de examinar, ou seja, afirmativa e transformativa. O eixo vertical inclui os dois aspectos da justiça que temos considerado, ou seja, redistribuição e reconhecimento. Nesta matriz podemos localizar as quatro decisões políticas que discutimos. Na primeira célula, onde a redistribuição e a afirmação se cruzam, está o projeto do Estado de bem-estar liberal, que superficialmente reatribui as proporções distributivas entre os grupos existentes, tende a apoiar a focalização entre os grupos e pode gerar, como efeito secundário, o desrespeito. Na segunda célula, onde se cruzam redistribuição e transformação, está o projeto socialista que, visando uma reestruturação profunda das relações de produção, tende a apagar a diferenciação entre grupos e pode também contribuir para corrigir algumas formas de desrespeito. Na terceira célula, onde o reconhecimento e a afirmação se cruzam, está o projeto de multiculturalismo central, centrado nas redistribuições superficiais de respeito entre grupos existentes e que tende a sustentar a diferenciação entre grupos. Na quarta célula, onde o reconhecimento e a transformação se cruzam, está o projeto de desconstrução; visa a reestruturação profunda das relações de 
reconhecimento, tende a desestabilizar os fatores de diferenciação entre os grupos (FRASER, 1997, p. 44-45, tradução nossa). ${ }^{3}$

Tal matriz identifica o multiculturalismo central como análogo cultural do Estado de bem-estar social, ao tempo que identifica a desconstrução como análoga cultural ao socialismo (FRASER, 1997, p. 46). A partir destas diferenciações, Fraser crê poder diferenciar até que ponto as soluções interferem entre si e se aplicam ao mesmo tempo. As soluções de cunho afirmativo de redistribuição do estado de bem-estar social parecem contradizer, para Fraser, as políticas de reconhecimento afirmativas, na medida em que uma tende a aumentar as diferenças e a outra diminuir. Analogamente, as políticas de redistribuição transformativas do socialismo parecem contrastar as políticas afirmativas do reconhecimento do multiculturalismo de base, tendo em virtude que as primeiras tendem a diluir a diferenciação dos grupos e as seguintes promovê-las.

Porém, ao mesmo tempo, vemos soluções que se combinam. As soluções centradas no estado de bem-estar social e no multiculturalismo central, ambas tendem a promover a diferenciação dos grupos, ainda que a primeira possa levar ao desrespeito. Na mesma linha, Fraser considera que as políticas transformativas de redistribuição do socialismo são compatíveis, sendo que ambas tendem a diluir os fatores de diferenciação entre os grupos, o que aproxima a autora de uma concepção deontológica.

Vemos que, a partir da exposição das ideias de Nancy Fraser, baseada na teoria do reconhecimento de Honneth, ela traz à tona de volta a luta de classes e as pautas políticoeconômicas para se pensar as transformações sociais rumo à emancipação da sociedade. Fraser, porém, não descarta o reconhecimento enquanto pauta, e para isso formula uma teoria bilateral, que busque abranger tanto as pautas de reconhecimento como de redistribuição. Assim, Fraser retoma o socialismo ao passo que o pensa enquanto a via transformadora das estruturas sociais, capaz de realmente modificar a estrutura econômico-política da sociedade,

\footnotetext{
${ }^{3}$ Imaginemos uma matriz de cuatro celdas. El eje horizontal incluye los dos tipos generales de soluciones que acabamos de examinar, es decir, las afirmativas y las transformativas. El eje vertical incluye los dos aspectos de la justicia que hemos venido considerando, esto es, la redistribución y el reconocimento. Sobre esta matriz podemos ubicar las cuatro orentaciones politicas que hemos discutido. Em la primeira celda, donde intersectan la redistribuición y la afirmación, se encuentra el proyecto del Estado liberal benefactor, que reasigna supercialmente las prociones distribuitivas entre los grupos existentes, tende a apoyar la direnciación entre los grupos, y puede generar, como efecto secundario, el irrespecto. En la segunda celda, donde intersectan la redistribuición y la transformación, se encontra el proyecto socialista que, dirigido a une reestruturación profunda de las relaciones de producción, tende a borrar la diferenciación entre los grupos y puede contribuir también a reparar algunas formas de irrespecto. En la tercera celda, donde intersectan el reconocimento y la afirmación, se encuentra el proyecto del multiculturalismo central, centrado em las redistribuiciones superficiales del respeto entre los grupos existentes y que tende a apoyar la diferenciación entre los grupos. Em la cuarta celda, donde intersectan el reconocimiento y la transformación, se encuentra el proyecto de la deconstrución; dirigido a la re-estructuración profunda de las relaciones de reconocimiento, tende a desestabilizar los factores de diferenciación entre los grupos (FRASER, 1997, p. 44-45).
} 
ao tempo em que o estado de bem-estar social não dá conta de tal tarefa. Também, em relação às questões de reconhecimento, apresenta a desconstrução na qualidade de ação transformativa eficiente na desestruturação das relações de dominação cultural, e no reconhecimento dos grupos subjugados, em contraste com as ações afirmativas do multiculturalismo central.

\section{Considerações finais}

Tendo em virtude o que foi abordado, começamos a discussão apresentando a concepção de reconhecimento desenvolvida por Axel Honneth em seu livro Luta por reconhecimento. A tese central aponta que a identidade dos indivíduos se determina por um processo intersubjetivo mediado pelo conflito e pelo reconhecimento. Assim sendo, a busca por uma proposta normativa se dá através do desdobramento de suas três dimensões - do amor, da solidariedade e do direito. Nesse sentido, os sujeitos e grupos sociais só são capazes de forma suas identidades na medida em que elas são reconhecidas nas relações com o próximo, na prática institucional e no convívio social.

Sem descartar a importância da noção de reconhecimento erigida por Honneth e por autores comunitaristas, como Charles Taylor, Nancy Fraser traz à tona para discussão a problemática das questões político-econômicas de redistribuição. De acordo com a autora, a redistribuição, em conjunto com o reconhecimento, aparece como um problema de relação institucionalizada de subordinação social, não configurando um problema essencialmente cultural, mas sim de status. A existência de leis que não designam status iguais para todos os sujeitos sociais e as relações que estabelecem, geram a necessidade de reconhecimento, a sua solução consiste em desinstitucionalizar os códigos que trazem subordinação social. Ao atribuir aos direitos uma dimensão universalista, ela entende que não devem ser feitas redistribuições voltadas para grupos específicos, uma vez que isso acabaria por gerar o não reconhecimento desses grupos específicos.

Os modelos críticos apresentados pelos autores nos anos 1990 permanecem atuais dentro do campo normativo. Ambos oferecem importantes instrumentos críticos de avaliação da realidade social e, principalmente, das políticas públicas voltadas para o reparo de injustiças econômicas, sociais, políticas e históricas. Além disso, a discussão revive o impasse histórico entre pensar políticas voltadas para grupos sociais específicos, historicamente oprimidos, e políticas de base deontológica, isto é, de caráter universal. Independente do caminho que se escolher, ambos os intelectuais oferecem caminhos para a reflexão dentro do 
campo da Teoria Crítica em torno das questões de cunho político normativo, indo além da crítica meramente descritiva, apontando para as possibilidades de transformação da realidade.

AGRADECIMENTOS: Agradeço a Isabela, pelo apoio, incentivo e carinho sem os quais não teria realizado este trabalho. Agradeço também ao Prof. Dr. Antonio Ianni Segatto, por ministrar a disciplina "Filosofia contemporânea" que deu origem a este artigo.

\section{REFERÊNCIAS}

ADORNO, T.; HORKHEIMER, M. Dialética do esclarecimento: fragmentos filosóficos. Rio de Janeiro: Jorge Zahar, 1985.

ALBORNOZ, S. G. As esferas do reconhecimento: uma introdução a Axel Honneth. Cad. psicol. soc. trab., São Paulo, v. 14, n. 1, p. 127-143, jun. 2011.

ARISTÓTELES. A política. São Paulo: Martins Fontes, 2002.

BRESSIANI, N. A. Economia, cultura e normatividade. O debate de Nancy Fraser e Axel Honneth sobre redistribuição e reconhecimento. 2010. 151 f. Dissertação (Mestrado em Filosofia) - Faculdade de Filosofia, Letras e Ciências Humanas, Universidade de São Paulo, São Paulo, 2010.

FRASER, N. Redistribución y Reconocimiento In: Iustitia interrupta: reflexiones críticas desde la posición "postsocialista". Santafé de Bogotá: Siglo del Hombre Editores, Universidad de los Andes- Facultad de Derecho, 1997.

HABERMAS, J. O discurso filosófico da modernidade. São Paulo: Martin Fontes, 2000.

HABERMAS, J. Teoria do agir comunicativo. São Paulo: Martin Fontes, 2012.

HABERMAS, J. Trabalho e interação. In: Técnica e ciência como "ideologia". Lisboa: Edições 70, 1987.

HONNETH, A. Crítica del poder: fases em la reflexión de uma teoria crítica de la sociedade. Madrid: Machado Libros, 2009.

HONNETH, A. Luta por reconhecimento: a gramática moral dos conflitos sociais. São Paulo, 2009.

HORKHEIMER, M. Autoridade e família. In: HORKHEIMER, M. Teoria crítica: uma documentação. São Paulo: Perspectiva, 1990.

HORKHEIMER, M. Teoria Tradicional e Teoria Crítica. In: HORKHEIMER, M.; ADORNO, T. Textos escolhidos. São Paulo: Nova Cultural, 1989.

NOBRE, M. A teoria crítica. Rio de Janeiro: Zahar, 2004. 


\section{Como referenciar este artigo}

PANIGASSI, P. L. Axel Honneth e Nancy Fraser: dilemas entre o reconhecimento e a redistribuição. Rev. Sem Aspas, Araraquara, v. 9, n. 2, p. 231-246, jul./dez. 2020. e-ISSN: 2358-4238. DOI: https://doi.org/10.29373/sas.v9i2.14695

Submetido em: 28/01/2021

Aceito em: 27/02/2021

Publicado em: 01/03/2021 